\title{
Carmen Miró: demógrafa y luchadora social*
}

\section{Manuel Ordorica**}

Carmen Miró es, sin duda alguna, el personaje latinoamericano más conocido en el mundo los estudios de población. Obtuvo el Premio de Población 1984 que otorga las Naciones Unidas en reconocimiento a su contribución a la formación de estudiosos en esta disciplina, y por su esfuerzo para promover y realizar investigación demográfica en la región latinoamericana. En ese año, por cierto, fue candidata a la presidencia de su natal Panamá. ¿Qué más se puede decir de Doña Carmen Miró que no se haya dicho ya? Todos la conocemos y la admiramos. Mujer brillante, íntegra y honesta. Destacada funcionaria pública, luchadora social, investigadora rigurosa y gran maestra. Es una referencia obligada en la enseñanza de los estudios en población de América Latina y persona clave en la formación de los pioneros demógrafos mexicanos.

Carmen siempre ha mostrado ser creyente en que la ciencia y el método pueden y deben contribuir al desarrollo económico, social y político: al desarrollo integral. Sus preocupaciones, empero, no se han limitado al plano teórico, sino que en todo momento ha buscado involucrarse en el campo de las políticas sociales. Logró apuntalar a la demografía como una ciencia capaz de responder a los problemas de la gente. A fin de cumplir con este propósito, en 1970 planteó la Conferencia Regional Latinoamericana de Población, en la cual se abordó la pertinencia de establecer políticas demográficas vinculadas a la planeación con la finalidad de mejorar la calidad de vida de las personas. Esta reunión conformó el terreno en el que descansa la definición de la nueva política de población de México. Es memorable el artículo que presentó en esa conferencia: "Política de población: ¿Qué? ¿Por qué? ¿Para qué? ¿Cómo?”. Trabajo que sin lugar a dudas continúa vigente. Dicho artículo estimuló la discusión y sirvió de base en la toma de decisiones en esferas gubernamentales y académicas, buscando conceptualizar la política de población en el contexto de la planificación global y coordinada con las metas de desarrollo. Señalaba que la

\footnotetext{
* Palabras pronunciadas en el Homenaje a Carmen Miró, El Colegio de México, 1 de septiembre de 2006.

**El Colegio de México. Correo electrónico: mordori@colmex.mx.
}

ESTUDIOS DEMOGRÁFICOS Y URBANOS, VOL. 22, NÚM. 2 (65), PP. 481-484 
planificación familiar no era sinónimo de política de población, y destacaba la importancia de integrar dicha política en la planeación sectorial.

En 1958 Carmen Miró se trasladó a Santiago de Chile para encargarse de la Dirección del Centro Latinoamericano de Demografía (Celade), institución desde donde impulsaría el desarrollo de la demografía en la región y convertiría a esta disciplina en una herramienta para la investigación social. Quizás una de las mayores contribuciones del Celade, siendo ella su directora, fue la formación de personal capaz de aplicar crítica y analíticamente las técnicas de análisis demográfico al estudio de las diferentes características de la población. En México, en 1964, colaboró en la creación de la maestría en Demografía en el entonces Centro de Estudios Económicos y Demográficos de El Colegio de México, hoy Centro de Estudios Demográficos, Urbanos y Ambientales.

Gracias al apoyo de Carmen Miró y a la visión de destacados investigadores como Víctor Urquidi, Gustavo Cabrera, Raúl Benítez Zenteno y luego José Morelos, los tres últimos egresados del Celade, al día de hoy El Colegio de México ha formado a 249 estudiantes de la maestría en Demografía y 64 del doctorado en Estudios de Población.

El impulso de Carmen a la demografía latinoamericana no se restringió a lo realizado en el Celade o en El Colegio de México; su influencia se ha dejado sentir en varios centros de la región latinoamericana y en oficinas gubernamentales orientadas a establecer políticas de población. Un ejemplo es su contribución a la fundación, en 1972, del Centro de Estudios Demográficos de la Universidad de la Habana en Cuba.

En 1976 Carmen se trasladó a El Colegio de México para presidir el Grupo Internacional de Evaluación de la Investigación en Ciencias Sociales sobre Población y Desarrollo, y para fungir como secretaria ejecutiva del Programa de Investigaciones Sociales sobre Población en América Latina (PISPAL), que patrocinaba el desarrollo de diversos estudios demográficos en instituciones especializadas de la región. Durante el periodo que estuvo en El Colegio, el Centro se benefició con sus sugerencias para mejorar el plan de estudios del posgrado. Asimismo realizó aportaciones importantes para la definición de la política de población de 1977, cuando Gustavo Cabrera encabezó el Consejo Nacional de Población (Conapo). En este mismo año terminó su gestión como presidenta de la Unión Internacional para el Estudio Científico de la Población. 
Sus logros científicos se complementan con su labor como profesora de varias generaciones de demógrafos, que hoy se encuentran formando a otros tantos, o están en la generación de información, o en la investigación, o definiendo las nuevas políticas de población. El sentido crítico y constructivo de Carmen en la investigación social ha sido un elemento formativo de gran valor para todos los que directa o indirectamente hemos estado cerca de ella.

Yo no tuve el privilegio de haber sido su alumno, pero quienes la tuvieron como profesora además de sentirse afortunados, la recuerdan con muchísimo cariño, afecto y admiración. Y se consideran afortunados no solamente por haber aprendido su materia, sino por haberle aprendido a ser mejores como seres humanos; con ella no cabían las falsas modestias, ni los alardes de conocimiento; valían la reflexión y la crítica constructiva, el conocimiento compartido y la opinión certera. Su carácter, convicción y firmeza son tres características que reúne para mejorar y cambiar las cosas. Afortunados porque les enseñó la importancia de estar totalmente entregados a lo que uno hace; porque cuando aceptaba que se había equivocado les enseñó a ser menos pretenciosos y soberbios, les enseñó a apoyarse en sus fortalezas, no en sus debilidades. Maestra estricta pero justa, siempre dispuesta a brindar un buen consejo, aunque muchas veces no fuera el que quisieran escuchar. Me comentan que les enseñó a decir "¿me explico?” y no "¿me entiende?”. Desde el primer día de clases ya ubicaba a los estudiantes por su nombre; y por ello cuando alguien le comentaba a Carmen que se le olvidan los nombres de las personas, ella le decía, "se te olvida algo muy importante: la primera característica de las personas, justo su nombre". Lo que les queda claro a todos es que los indujo a estudiar con seriedad y responsabilidad los temas de población.

Recuerdo con mucho aprecio un comentario crítico que hizo a mi trabajo sobre la evaluación de la mortalidad infantil en Mazatepec, en el estado de Morelos. Los modelos para estimar la mortalidad en la niñez daban resultados de dudosa interpretación. La evaluación la hice en campo y combinaba lo cuantitativo con lo cualitativo. Con sus comentarios me percaté de su profundidad y amplio conocimiento de las estadísticas demográficas. El comentario me permitió mejorar el documento, pero lo más importante es que me enriqueció como investigador. Su crítica fue aleccionadora.

En fin, la influencia de Carmen Miró en las instituciones mexicanas y latinoamericanas y en las personas -yo incluido- ha sido decisiva. 
Por eso estoy convencido de que El Colegio de México, por medio del Centro de Estudios Demográficos, Urbanos y Ambientales, ha seleccionado a una persona extraordinaria y más que merecedora de este homenaje.

Los demógrafos mexicanos nos sentimos muy honrados de haber sido receptores de sus enseñanzas. Ojalá que con nosotros trascienda su espíritu crítico y su compromiso social. Ella ha plantado las semillas para que los demógrafos de ahora y los que vendrán después puedan cosechar los frutos sembrados por ella. 